\title{
Enhancing Student Interactions in Online Learning: A Case of Using YouTube in a Distance Learning Module in a Higher Education Institution in Uganda
}

\author{
Proscovia Namubiru Ssentamu, ${ }^{1, *}$, Dick Ng'ambi ${ }^{2}$, Emily Bagarukayo $^{3}$, Rehema Baguma ${ }^{3}$, \\ Harriet Mutambo Nabushawo ${ }^{4}$, Christine Nalubowa ${ }^{5}$ \\ ${ }^{1}$ Department of Educational Leadership and Management, School of Management Sciences, Uganda Management Institute, Kampala, \\ Uganda \\ ${ }^{2}$ Educational Technology Inquiry Lab, School of Education, University of Cape Town, Cape Town, South Africa \\ ${ }^{3}$ Department of Information Systems, School of Computing and Informatics Technology, College of Computing and Information Sciences, \\ Makerere University, Kampala, Uganda \\ ${ }^{4}$ Department of Open, Distance and eLearning, School of Distance and Lifelong Learning, College of Education and External Studies, \\ Makerere University, Kampala, Uganda \\ ${ }^{5}$ Department of Regulation and Compliance, Directorate of Regulation and Legal Services, National Information Technology Authority, \\ Kampala, Uganda
}

\author{
Email address: \\ spnamubiru@gmail.com (P. N. Ssentamu), psnanmubiru@umi.ac.ug (P. N. Ssentamu), Dick.Ngambi@uct.ac.za (D. Ng’ambi), \\ ebagarukayo@cit.ac.ug (E. Bagarukayo), rbaguma@cit.ac.ug (R. Baguma), hnabushawo@gmail.com (H. M. Nabushawo), \\ Christine.Nalubowa@nita.go.ug (C. Nalubowa) \\ *Corresponding author
}

\section{To cite this article:}

Proscovia Namubiru Ssentamu, Dick Ng'ambi, Emily Bagarukayo, Rehema Baguma, Harriet Mutambo Nabushawo, Christine Nalubowa. Enhancing Student Interactions in Online Learning: A Case of Using YouTube in a Distance Learning Module in a Higher Education Institution in Uganda. Higher Education Research. Vol. 5, No. 4, 2020, pp. 103-117. doi: 10.11648/j.her.20200504.11

Received: April 19, 2020; Accepted: May 14, 2020; Published: June 15, 2020

\begin{abstract}
One of the challenges facing higher education institutions in general and Uganda in particular, is the widening gulf between increased use of technology for teaching and learning and achieving meaningful learning outcomes, especially in the face of the COVID-19 pandemic. In this paper, we report on one use of technology where a teacher's integration of YouTube videos in teaching increased students' levels of interaction with the content of the video, with peers and with the instructor (teacher). Guided by the sequential mixed-method design, a series of online learning activities were designed and matched with a carefully selected YouTube video. The activity was piloted and refined for use on purposefully selected teaching staff. The staff watched the videos that were uploaded on the Virtual Learning Environment (VLE) and responded to online learning tasks at individual and group levels. The VLE served as a knowledge sharing space for reflections. The paper concludes that lesson design was critical in enriching the VLE with carefully selected YouTube videos. Our key recommendations are: focus on the learning outcomes, design for the desired interactions, build into the task reflections, and decide whether to pre-select YouTube videos for students or to allow students to find appropriate YouTube videos; use reflections and knowledge sharing spaces. Further work has built reflective questions in the video which allows student to pause and reflect.
\end{abstract}

Keywords: Digital Taxonomy, Distance Learning, Higher Education, Interactive Learning, Student Pedagogical Support, Virtual Learning Environment, YouTube

\section{Introduction}

Current trends in higher education show an increasing demand for online education and students' expectation for meaningful learning with emerging technologies [1]. The changing needs of online learners demand that online 
instructors are re-skilled on transformative pedagogies that have potential to achieve meaning learning with emerging technologies [1-4], understand uses of technology in teaching and learning [5] and are instrumental in ensuring practices are diffused at an education institution [6]. A number of technologies are available to support online education including Learning Management Systems (LMS), Course Management System (CMS), Podcasts, Vodcasts, Social Networking, Research Databases, Instant Messaging, eBooks, electronic portfolios Internet phone, wikis, simulations, text messaging, podcasting, wikis, blogs and a whole range of social media and their affordances, including YouTube, Facebook, Twitter, Instagram, Vine, Pinterest, SnapChat and LinkedIn [7]. However, research on online interactivity using various technologies to support students' learning, especially in the context of Uganda's higher education, the use of the Virtual Learning Environment (VLE) is still limited [8, 9 and 10]. Yet online interactivity, including but not limited to YouTube, is capable of keeping students interested and excited about their own learning, and consequently enabling them to achieve the intended learning outcomes and graduate on schedule. Students are already familiar with YouTube and therefore no further training is required.

This paper investigates how YouTube was used to improve online interaction using as espoused by Anderson's six-types of interaction [11], Bower's [12] affordance analysis and Digital Bloom's digital taxonomy [13].

The paper is laid out as follows: the contextual background, theoretical underpinnings, the concept of online learning interaction, the thesis, educational purpose of using YouTube to improve online interaction using Anderson's [11] online interaction framework, Bower's [12] affordance analysis and Bloom's digital taxonomy [13] the procedure used, proof of concept, discussion and lessons learned.

\section{Contextual Background}

Several higher education institutions in Uganda have established fully-fledged Distance Learning (DL) Units running various distance learning programmes on the virtual learning environment, predominately using Moodle. A number of such programmes were originally conventional face-to-face (f2f) programmes and later converted into DL programmes for various reasons. Currently, these two programmes continue to run parallel to each other, i.e. as campus-based and as DL courses. The DL programmes run for one to two academic years whereas the $\mathrm{f} 2 \mathrm{f}$ programmes run for one academic year.

The VLE platforms are commonly structured to contain the following site pages: Students (their contact details), Forum posts (posts and discussions), Blogs (site blogs and site badges), Notes, Tags, Calendar, Students' Planner per program, Site news, Coursework results, Dates for examinations, Dates for face-to-face, Student profile, General announcements, Student inquiries, Course Unit/Module Handouts and Course Unit/Module coursework. Each Course Unit/Module has two to three lecturers/facilitators in addition to administrative staff, that is; training coordinator, DL Expert, e-learning expert, ICT expert and an administrative assistant. These are required to provide students both academic and administrative support throughout the course of study. Similar to offline course units/modules, course units/modules on the VLE are structured to include the following key areas: learning outcomes; credit units and delivery; course units/module leader; course units/module content and assessment structure.

In order for Higher Education Institutions (HEIs) in Uganda to build capacity to run the DL programmes, some institutions organise semester workshops to orientate and train staff on the VLE. Experts from various institutions are invited to provide training to staff. Students on the DL programs are also given refresher courses on the VLE every semester. To ensure quality of DL programs, students complete end of course unit/module/program evaluation on the teaching and learning interactions, the content, the tools used, among others. Reports are generated for decision making and improvement.

Other than the above efforts, there have been modest studies on the nature and level of interaction using asynchronous communication tools to motivate students to learn, to enable students assess and improve on their own learning, to create and to share in their learning community in the context of Uganda higher education VLE [8,9 and 10]. Anderson underscores the role communication technologies play in enhancing interaction between the key stakeholders in the educational transaction [11]. The move to the DL option in several HEIs was among others, intended to provide flexibility in learning in terms of time and space and increase student enrolment amidst limited space and staff. However, from an academic viewpoint, learner self-regulation skills in a blended educational context are predictive of academic success [14]. In their study, Lynch and Dembo [14] highlighted five self-regulatory attributes predictive of academic performance, i.e. intrinsic goal orientation, self-efficacy for learning and performance, time and study environment management, help seeking, and Internet self-efficacy, of which there is limited documentation on the level of online interactivity at HEIs in Uganda.

\subsection{Theoretical Underpinning of the Study}

It is noted: '...online learning theory needs to help educators to decide which of the many technological options is best suited for their application' [11, page 42]. However, based on the argument that technology by itself cannot transform the pedagogy [15], in order to decide on the choice of the technology to use, there are key fundamental questions one has to reflect on, i.e. why use a particular technology? what content should be developed using that technology? how should the technology be used? Where should the technology be used?, and when should the technology be used? In other words, the user should deeply reflect on the affordances of the technology and whether it has features to support a learning activity aimed at promoting learner- and community-centered approaches in learning and assessment.

The literature on active and deep learning suggests that most students do not internalise and can neither understand nor apply 
learning, unless they are actively involved in it [16, 17, 18 and 19]. Various basic theories of education can be used in online learning, but with modification. The most common among these include behaviourism, cognitive and constructivism theories. Online learning-based theories propounded in the literature concur with the need for learners to be at the centre stage in their own learning, and to actively participate in it. However, current trends point towards the importance of the constructivist instructional design theory which stresses individual discovery and construction of knowledge [20, 11, and Jonassen, 1991 cited in 11] and Bloom's digital taxonomy [13]. This study is also based on Bloom's digital taxonomy and uses constructivism as its theoretical lens.

It is observed that although some discussions in the literature relate to effective practices in the use of emerging technologies for online education, empirical evidence to support or refute the effectiveness of such technologies, or, perhaps more importantly, guidance on how to use such tools effectively based on empirical evidence, is lacking [4, page 24). The current study does not aim to provide such empirical evidence, but with reference to the already existing frameworks and theories proposes to review and improve various levels of online interactions with a view to motivate students and improve the achievement of the intended learning outcomes.

\subsection{Conceptualizing Interaction in Online Learning}

An effective learning environment is framed within the convergence of four overlapping lenses, i.e. learner-centred, knowledge-centred, assessment-centred and community-centred [Bransford, Brown and Cocking, 1999, cited in 11, page 35]. In a learner-centred context, focus is on the learner, the learning process and outcomes. The higher education institution should therefore create an environment that supports the learner in terms of the staff and the educational infrastructure. Learning is sequential, beginning from what the learners know to what they have to know based on their interest and need. According to Bransford et al., [cited in 11, page 35), 'the learning environment respects and accommodates the particular forms of expression, that the learner uses to build knowledge.' The same thinking has to be taken into consideration in designing online programs, and probably much more is needed since the media of communication is different in such an asynchronous context. Reference [11] notes that the online learning environment has a unique cultural context and cites Benedikt (1992) who argued: “...cyberspace has a geography, a physics, a nature and a rule of human law' [11, page 36]. This means that HEIs and particularly the staff and students on DL programmes have to think and act slightly differently from the way we think and act when designing and implementing offline educational programs. Our expert knowledge and skill in designing and implementing offline programs is not the same expertise we require to design online programs, since although the content and learning outcomes are similar, the processes are different. Current temptation is however, to think the same way in using online programs, as we think in using offline $\mathrm{f} 2 \mathrm{f}$ programs. For instance, in designing and implementing online programs, lecturers will need online leadership skills, Internet efficacy skills, Internet communication skills, and netiquette in addition to taking into consideration the learners' various backgrounds as they seek to create an enabling online learning platform for all.

Apart from the learner-centred context, the VLE has to focus on knowledge or content the learner and the lecturers will engage with. Unfortunately this seems to be the primary focus on most offline f2f programs. In Uganda's higher education system, there is a shift from teaching content, just for the sake of it, to emphasise competences and learning outcomes [21]. Higher education institutions are required to design programs that reflect labour market needs and that satisfactorily usher the graduate into the world of work, i.e. knowledge transfer. For instance, learning outcomes should be stated in such a way that what the graduate should be able to do at the end of a particular program is evident. This shift in thinking has encouraged relevant stakeholders to participate at different stages in the curriculum development process, including professional bodies, employers, standards agencies, alumni, students, and subject and learning experts. However, designing a good program is one thing, and ensuring that learners acquire the needed competences is another. Therefore, the learning process is vital in the successful implementation of a given program. In the case of this study, online campus-based programs seem to demand much more careful thought in creating an enabling environment for learning to take place in the absence of a lecturer for most if not all the time compared to the offline programs we are used to. It is noted;

...the Net provides expanded opportunities for students to plunge ever deeper into knowledge resources, thus affording a near limitless means for students to grow their knowledge, to find their own way around the knowledge of the discipline, and to benefit from its expression in thousands of formats and contexts [11, page 37].

Perhaps this is one of the biggest advantages that can be obtained in providing online educational programs, but if not carefully designed, there is a danger for students not to benefit from the online programs as campus-based students. Further, in designing online based programs centred on a knowledge base, key is the knowledge levels (cognitive levels), how such knowledge is structured, how it links with other knowledge at disciplinary, interdisciplinary and trans-disciplinary ways; as well as how such knowledge links with the world of work. There is a possibility of uploading offline programs on the Net as they are, especially if the course designers lack the skill and commitment to designing online programs. Nonetheless, online programmes designed based on the learner-centred and knowledge-based frames of reference will go a long way in designing and implementing successful online programs.

According to Bransford et al., [1999 cited in 11], assessment-centred perspective to learning in general does not only focus on summative but more so on the formative assessment that aims '...to motivate, inform, and provide feedback to both learners and teachers' (p. 38). Online educational assessments take several forms including self-assessment (reflection), peer assessment, teacher 
assessments as well as computer-based assessment; and can be formative or summative, or a hybrid. Reference [11] provides an array of computer-marked assessments including quizzes, simulation exercises, virtual labs, online automated tutors, and sophisticated software tools. However, understanding what is more useful than what is most easy to asses has proved challenging for online course designers [11]. This also raises questions about why assess?, what to assess?, how to assess?, when to assess? and where to assess?. For instance, in a learner-centred context, the knowledge (content) should guide us in responding to those five questions. If the content is pitched to the learners' level as would be the case in the formulated learning outcomes, taps Higher Order Thinking skills (HOTs) including during delivery, is related to the world of work, it then follows that the assessments should also tap HOTs and is work-related. This is referred to as constructive alignment [22, 23]. According to Reference [22];

The fundamental principle of constructive alignment is that a good teaching system aligns the teaching method and assessment to the learning activities stated in the objectives so that all aspects of this system are in accord in supporting appropriate student learning [22, page 25].

In addition, unlike offline assessments, online assessments should exploit the opportunity afforded by for instance, the interaction between student with content (including other e-resources not included in the course outline, but relevant to the course), students with students, and student with lecturer. These alternative sources of assessments are likely to reduce the lecturers' assessment workload whereas maintaining high-level student and lecturer motivation and interest on the course.

The fourth perspective to learning is the community-centred perspective [11]. Citing Vygotsky's (1978) social cognition, Lipman's (1991) community of inquiry and Wengers' (2001) community of practice, [11] underscores the importance of students working together in an online context to create new knowledge collaboratively, and further notes '...with a shared sense of belonging, trust, expectation of learning, and commitment to participate and to contribute to the community' (Wilson, 2001, cited in 11, page 39]. Key in a community-centred online approach to education is interaction, which Wagner (1994: 8) defines as reciprocal events that require at least two objects and two actions. Interactions occur when these objects and events mutually influence one another' [cited in 11, page 43]. The functions of interactivity have been documented to include:

a) allowing for learner control, facilitating program adaptation based on learner input, allowing various forms of learner participation and communication, and acting as an aid to meaningful learning [Sims, 1999 in 11, page 43].

b) creating learning communities [Lipman, 1991 and Wenger, 2001 cited in 11, page 43].

c) valuing other people's perspectives based on constructivist learning and inducing mindfulness in the learners [Jonassen, 1991 and Langer, 1989 cited in 11, page 43].
Anderson developed six levels of interaction including student-student interaction, student-teacher interaction, student-content interaction, teacher-teacher interaction, teacher-content interaction and content-content interaction [11, page 43]. Interactivity should be the primary criterion for selecting media for educational delivery [Bates, 1991 cited in 11, page 44]. However, in making this choice, one has to be mindful whether the level of interaction is learner-centred, instruction-centred or teacher-centred. The more the interaction is learner-centred, the further the level of interaction between the student and teacher in terms of distance and time. The current study delimited itself to three levels of interactions, i.e. student-student interaction, student-teacher interaction, and student-content interaction.

Student-student interaction in offline education is where students physically interact with peers in real time and space; for example, either in groups or in collaborative tasks in the presence or absence of a teacher-cum-lecturer. In online education, such interaction takes place in a VLE and is key in promoting, investigating and developing multiple perspectives, collaboratively learning, and in the development of critical social skills in education, and communities of learning (Slavin, 1995 and Wenger et al., cited in 11].

Student-teacher interaction in an offline engagement is where students physically interact with their teacher (s) in real time and space, e.g. in a lecture room setting. The interaction could be one-on-one, or between a group of students with their teacher (s). In online education, such interaction can be supported by text, audio or video [11]. One of the advantages of this mode of interaction is the immediacy of feedback promoted through dialogue as well as interpreting nonverbal queues accompanying the verbal communication, especially in the offline mode.

In student-content interaction, the student interacts with online content to foster learning. There is a host of web-based content in the virtual library, online computer-assisted tutorials, as well as e-Books, e-Journals, and institutional-designed content uploaded on the LMS [11]. Among the advantages is the ability of online content to be modeled to suit the user's preferred environment and learning path, and its capacity for immediate feedback [11], for example, through job aids.

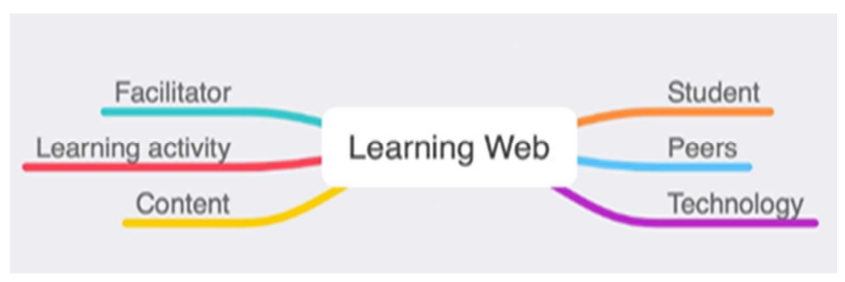

Figure 1. The Learning Web (adapted from [15]).

Online learning is separation of instructor and student in space and time, with connections through educational media where the learner takes an active role in the learning process [15]. Therefore, it is up to the student to make sense of the body of knowledge associated with the course being delivered [15]. The instructor supports this process through the use of 
collaborative assignments, facilitation of active discussion, and promotion of the development of critical thinking and research skills. Reference [15] designed a learning web, similar in focus to Anderson's [11] interaction framework, presented in Figure 1.

The four perspectives (Bransford et al., 1999 cited in 11], and the three levels of interaction [11] reviewed above defined the dimensions of student support in the current study. For successful online student support, the four perspectives and three levels of interaction are significant and cannot be considered singly, but as a whole when designing and implementing online programs. Student support is perceived differently in the literature depending on the context and focus. For instance, elsewhere, student support was considered from an administrative viewpoint and therefore covering themes such as scheduling of teachers, students, teaching activities, assessment time and module resources including teaching rooms, laboratories, library facilities and equipment [24]. However, their focus was on campus-based programs. The researchers added that such support can be technically subject-specific, audio-visual, information skills or information technology.

In the current study, student online pedagogical support transcends provision of administrative support to refer to the online strategies to promote interactivity and therefore deeper student learning and engagement using the VLE. Such support has been considered as the extent to which online education is of '...relevance, interactive, project-based and collaborative nature of online instruction, while providing learning with some choice or control over their learning,' [Partlow \& Gibbs in 4, page 23] based on the premise that these are adult learners. Another study by Keeton is cited in which the effectiveness of online instructional strategies was described in terms of its ability to 'create an environment that supports and encourages inquiry,' 'broaden [s] the learner's experience of the subject matter,' and 'elicit [s] active and critical reflection by learners on their growing experience base' [Keeton, 2004 in 4, page 23]. Drawing on Bloom's digital taxonomy such support should tap HOTs, i.e. analyzing, evaluating and creating [13], and aimed at fostering various forms of interactions [11]. This is because the students on these courses are adults, who as learners are autonomous, self-directed, goal-directed, relevance-oriented, practical and have accumulated a foundation of life experiences and knowledge; therefore training must be useful to them in their work [25]. Similarly, adults prefer learning situations which are practical and problem-centered, promote their positive self-esteem, integrate new ideas with existing knowledge, show respect for individual learners, capitalize on their experience, and allow choice and self-direction (Goodlad cited in 27] Therefore, in this study the teaching and learning using YouTube was assumed to improve online interactivity on the DL programs in HEIs in Uganda.

\subsubsection{Thesis}

The thesis in the current study is that when students interact with carefully selected YouTube videos that have been uploaded on the VLE, student-content interaction, student-student interaction and student-online teacher interaction is likely to improve. In their study it is noted that the next [current] generation Course Management System (CMS) should be used as an avenue to promote rich and interactive experiences and a system that fosters a more learner-centered environment that is rich in critical thinking, student exploration, peer learning and knowledge construction, interdisciplinary experiences incorporating a community of educators (e.g. practitioners, business leaders, alumni) [4], and educational opportunities (Weigel, 2005, cited in 4]. Unfortunately, whereas the use of technology in teaching and learning is now widespread, its educational effectiveness is still subject to question [1,2, and 5]. It is not surprising therefore that for instance the CMS environments are used to manage learners rather than to foster deeper student learning and engagement [4]. Similar to other contexts, this observation is valid in Uganda's higher education setting.

Our review of the current VLE platforms in most HEIs in Uganda shows that the three levels of interaction i.e. student-student interaction, student-tutor interaction and student-content interaction [11] are underutilized. What is evident is frequent student-administrator interaction more focused on assessment deadlines, enquiries and updates on release of results and less on interaction that fosters learning. Similar findings have been observed in an unpublished study [26]. During the study, the researchers found nothing posted on the news forum and no provision for students to reflect on what they have learned. Under the individual course unit/module sessions, they noted more content exposure similar to the $\mathrm{f} 2 \mathrm{f}$ programs, more administrative postings from the Heads of Departments and Online Administrators on enquiries about assignments, feedback, and deadlines, but less on pedagogical support. Table 1 shows the frequency of module support provided to DL students.

Table 1. Frequency of module support provided to DL students between April and October.

\begin{tabular}{|c|c|c|c|c|c|c|c|c|c|c|}
\hline Module & Activity & April & May & June & July & Aug & Sept & Oct & Facilitators & Coordinator \\
\hline \multirow{6}{*}{$\begin{array}{l}\text { Research } \\
\text { Methods }\end{array}$} & Discussion Forum Queries \& inquiries & $\mathrm{x}$ & $\mathrm{x}$ & & & & & & & \\
\hline & Submission of Course work & & & $\mathrm{x}$ & $\mathrm{x}$ & & & & & \\
\hline & Release of coursework marks \& feedback & & & & & $\mathrm{x}$ & & & & \\
\hline & Discussion Forum after feedback & & & & & $\mathrm{x}$ & $\mathrm{x}$ & $\mathrm{x}$ & & \\
\hline & Self-paced Quiz & & & $\mathrm{x}$ & & & & & & \\
\hline & Revision summary uploaded & & & & & & $\mathrm{x}$ & & & \\
\hline \multirow{4}{*}{$\begin{array}{l}\text { M\&E } \\
\text { Principles \& } \\
\text { Perspectives }\end{array}$} & Discussion Forum Queries & $\mathrm{x}$ & $\mathrm{x}$ & $\mathrm{x}$ & $\mathrm{x}$ & $\mathrm{x}$ & $\mathrm{x}$ & $\mathrm{x}$ & & \\
\hline & Release of coursework marks \& feedback & & & $\mathrm{x}$ & $\mathrm{x}$ & & & & & \\
\hline & Discussion Forum after feedback & & & & & $\mathrm{x}$ & & & & \\
\hline & Self-paced Quiz & & & & & $\mathrm{x}$ & $\mathrm{x}$ & $\mathrm{X}$ & & \\
\hline
\end{tabular}




\begin{tabular}{|c|c|c|c|c|c|c|c|c|c|c|}
\hline Module & Activity & April & May & June & July & Aug & Sept & Oct & Facilitators & Coordinator \\
\hline \multirow{7}{*}{$\begin{array}{l}\text { M\&E in the } \\
\text { Public Sector }\end{array}$} & Revision summary uploaded & \multirow{7}{*}{$\mathrm{x}$} & \multirow{7}{*}{$\mathrm{x}$} & $\mathrm{x}$ & & \multirow{3}{*}{$\mathrm{x}$} & \multirow{3}{*}{$\mathrm{x}$} & \multirow{3}{*}{$\mathrm{x}$} & & \\
\hline & Discussion Forum Queries \& inquiries & & & $\mathrm{x}$ & $\mathrm{x}$ & & & & & \\
\hline & Submission of Course work & & & $\mathrm{x}$ & $\mathrm{x}$ & & & & & \\
\hline & Release of coursework marks \& feedback & & & & & $\mathrm{x}$ & & & & \\
\hline & Discussion forum after feedback & & & & & $\mathrm{x}$ & $\mathrm{x}$ & $\mathrm{x}$ & & \\
\hline & Self-paced Quiz uploaded & & & $\mathrm{x}$ & & & & & & \\
\hline & Revision Notes uploaded & & & & & & $\mathrm{x}$ & & & \\
\hline
\end{tabular}

Source: Primary data.

In another instance, on the site blog, students posted the following inquiries:

Is there a possibility for us to know the exact exams timetable, detailing the course module, date, time and venue when they will be done? (S3).

Rumour is that exam results are out, can administration confirm that and help those who are distant to access theirs (S7).

On one of the VLE platforms reviewed, nine (9) out of the 28 students were inactive on the discussion forum. The course administrator with concern made the following post on the discussion forum:

I have noted that Emmanuel [not actual name] alone is participating on the forum. Students taking this module make sure you actively participate and engage your lecturers through this forum as this will prepare you for your exams and also equip you with the knowledge and skills you need to perform in your work places. We are monitoring the discussions and will provide a feedback to the Academic Registrar's Office, so please take part (CA1).

Although, for instance discussion forums should be used as tools to promote conversational modes of learning, the current VLE in the above sampled typical HEI provided limited student-student, student-content, student-teacher interactivity. This may have been due to the nature of the task designed. The situation in individual sessions under each course unit was not unique. The various forms of interactions were limited, apart from a few questions posted in some sessions under 'Test your Understanding,' which also tested more of the Lower Order Thinking Skills (LOTs) than the HOTs. For example, the following question was posted under one of the sessions of a program: 'describe the generic steps within a project cycle'. Such a question requires a student to have basic knowledge on project implementation.

One HEI was used as a case study to explore how interactivity of the online approach on the DL programs could be improved. Figure 2 displays module activities, before we added in two case studies. This means that the VLE relies more on text and less on other technologies that promote online learning interaction. Although there is provision for interactivity, this is underutilized by the lecturers and students.

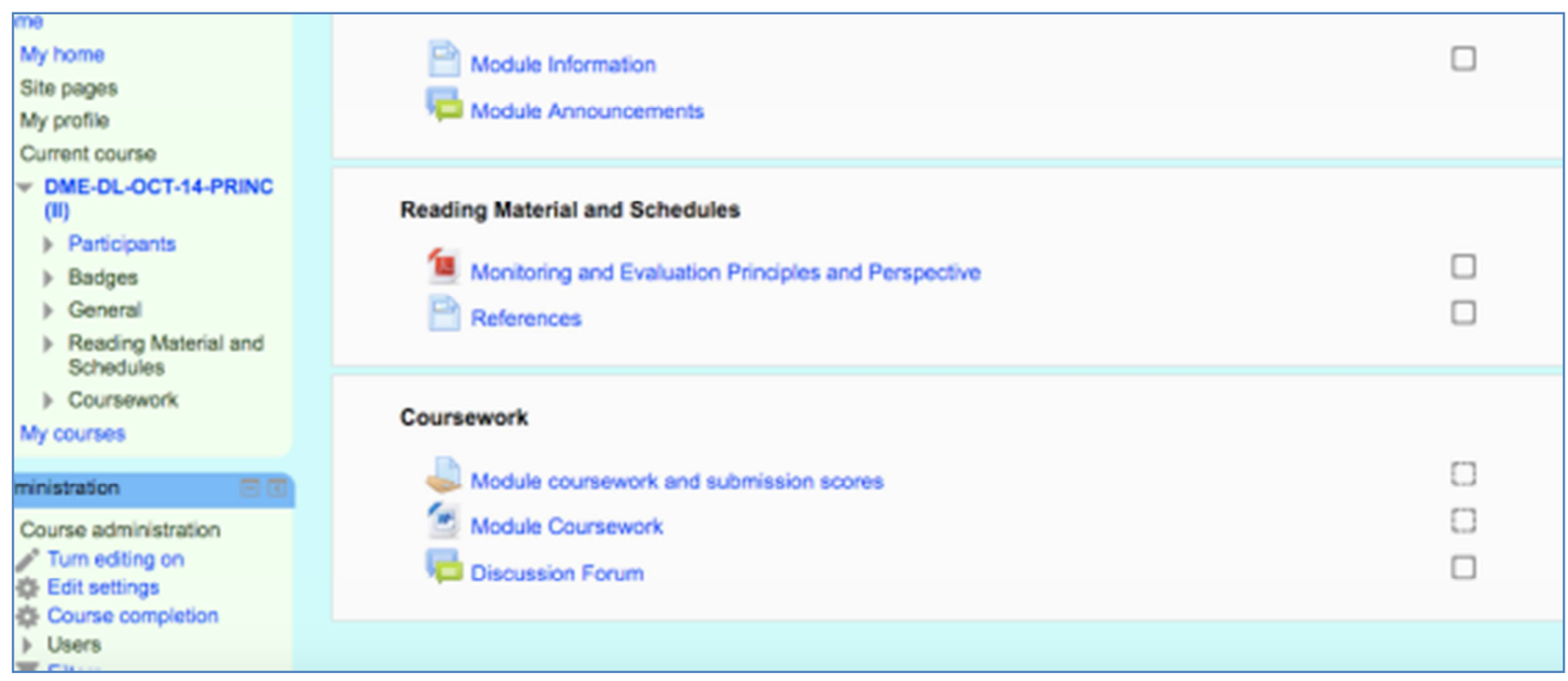

Figure 2. Module activities before the intervention.

The researchers' overall assessment is that the VLE of the sampled HEIs was not fully exploited to tap the various forms of interactions it affords and integrate various educational technologies to tap HOTs. Discussion forums for instance, should be used as tools to promote conversational modes of learning [28]. This points to a gap in task design vitally needed to improve on online interaction.

\subsubsection{Educational Purpose for Using YouTube}

To improve interaction in online learning using YouTube as an emerging educational technology [11] online interaction framework, Bower's affordance analysis [12], Bloom's digital taxonomy [13], and the constructivist theory were used.

The specific objectives for using YouTube were to integrate 
YouTube videos in the VLE to improve:

a) student-student interaction,

b) student-content interaction,

c) student-facilitator interaction,

d) collaborative learning,

e) active learning by tapping higher order thinking skills,

f) expand students' repertoire of learning beyond the course handbook,

g) fun during learning.

The target group was four lecturers who facilitate online learning. These were purposely selected as the students to provide feedback regarding online interaction using a YouTube video.

At the end of the session, students were expected to be able to:

a) read the session on communication styles in the online module handbook.

b) watch and explain the nature of communication in a YouTube video posted on VLE.

c) analyze the enablers and barriers to communication in the video.

d) make a presentation of their choice using various technologies.

e) record and upload their presentations on VLE.

f) critique their peers' presentations online.

g) assess their learning.

Note: due to time challenges, the students attempted questions 1-3.

\section{Methodology Used in Designing the Learning Intervention}

The following procedures were used to develop the online interactive activity; the researchers;

a) consulted staff in the DL and in the ICT Departments to support our familiarization with the VLE.

b) scanned the literature on current knowledge and practice trends and gaps in online teaching and learning.

c) selected the communication skills session taught in one of the course units in an online postgraduate course.

d) reviewed the course handbook to familiarize themselves with the module and session learning outcomes, the content, as well as identify the interaction gaps that needed to be filled at session level guided by the online interaction framework [11], the digital taxonomy [13] and the affordance analysis [12].

i. formulated the educational purpose, learning outcomes and developed learning activities for the session, guided by the online interaction framework and Bloom's digital taxonomy. The selected learning activities were appropriately mapped on identified knowledge areas (Table 2) in the session further guided by criteria for selecting learning activities which include: clarity, authenticity, economy validity, relevance/utility, comprehensiveness, variety, suitability, vividness, and interesting $[1,29,30]$.

ii. reviewed literature on online interaction to identify the affordances of various technologies that could enhance the development of the desired interactions and achieve the desired learning outcomes.

iii. based on the review, created a YouTube video on communication skills that could enable the researchers to 'scaffold progressive inquiry', 'structure and coordinate activity' and 'support community building' [Rubens, et al., cited in 12, page 4].

iv. further refined the learning activities and matched them with the selected technology, i.e. YouTube video guided by the affordance analysis [12].

e) shared with members of staff from the two Departments the educational purpose, learning outcomes and activities as well as the assignment; and asked for permission to upload these on the VLE.

f) a special online discussion forum of a group of four staff was created to enable piloting of the intervention.

g) received, reviewed and analyzed feedback to ascertain whether the tool improved interaction.

h) wrote the final paper to disseminate the findings.

Such an approach is described as 'sequential mixed-method design' [32]. The researchers preferred to use this sequencing in order to obtain some logical procedure in designing the activity and selecting the technology. They also preferred to involve the internal stakeholders, i.e. staff, in order for them to participate, reflect on and identify the current gaps in using the VLE, own the development process and the outcome when it is finally developed. According to Thurmond, the benefits of using the sequential mixed-method design include

...increasing confidence in research data, creating innovative ways of understanding a phenomenon, revealing unique findings, challenging or integrating theories, and providing a clearer understanding of the problem [2001: 254 cited in 5].

It is important to involve relevant stakeholders to elicit meaningful information in reviewing and improving curricula [24]. Table 2 shows the sketched matrix the researchers developed as a road-map to guide in matching the learning activity to the mediating circumstances and to Bloom's digital taxonomy.

Table 2. Learning activity, mediating circumstances and Bloom's Taxonomy in improving interaction with YouTube on VLE.

\begin{tabular}{|c|c|c|c|c|}
\hline Learning activity & \multicolumn{3}{|c|}{ Mediating circumstances } & Bloom's Digital Taxonomy \\
\hline Interaction & Context & Technology & Agents & $\begin{array}{l}\text { Cognitive levels: Remembering, Understanding, } \\
\text { Applying, Analyzing, Evaluating, Creating }\end{array}$ \\
\hline $\begin{array}{l}\text { Exposition } \\
\text { [student-content } \\
\text { interaction } \\
\text {-introduction]. }\end{array}$ & $\begin{array}{l}\text { Setting: } \\
\text { Flexible, e.g. home, } \\
\text { office, etc. }\end{array}$ & $\begin{array}{l}\text { Time: Asynchronous: } \\
\text { interactions between facilitator } \\
\text { and learners; learner and video, } \\
\text { learner and computer happen }\end{array}$ & $\begin{array}{l}\text { Facilitator, } \\
\text { Peers, } \\
\text { Technician } \\
\text { Supporters: }\end{array}$ & $\begin{array}{l}\text { Remembering through recognizing, identifying content } \\
\text { read in the session, YouTube video and online learning } \\
\text { activities. } \\
\text { Understanding through interpreting, inferring, }\end{array}$ \\
\hline
\end{tabular}




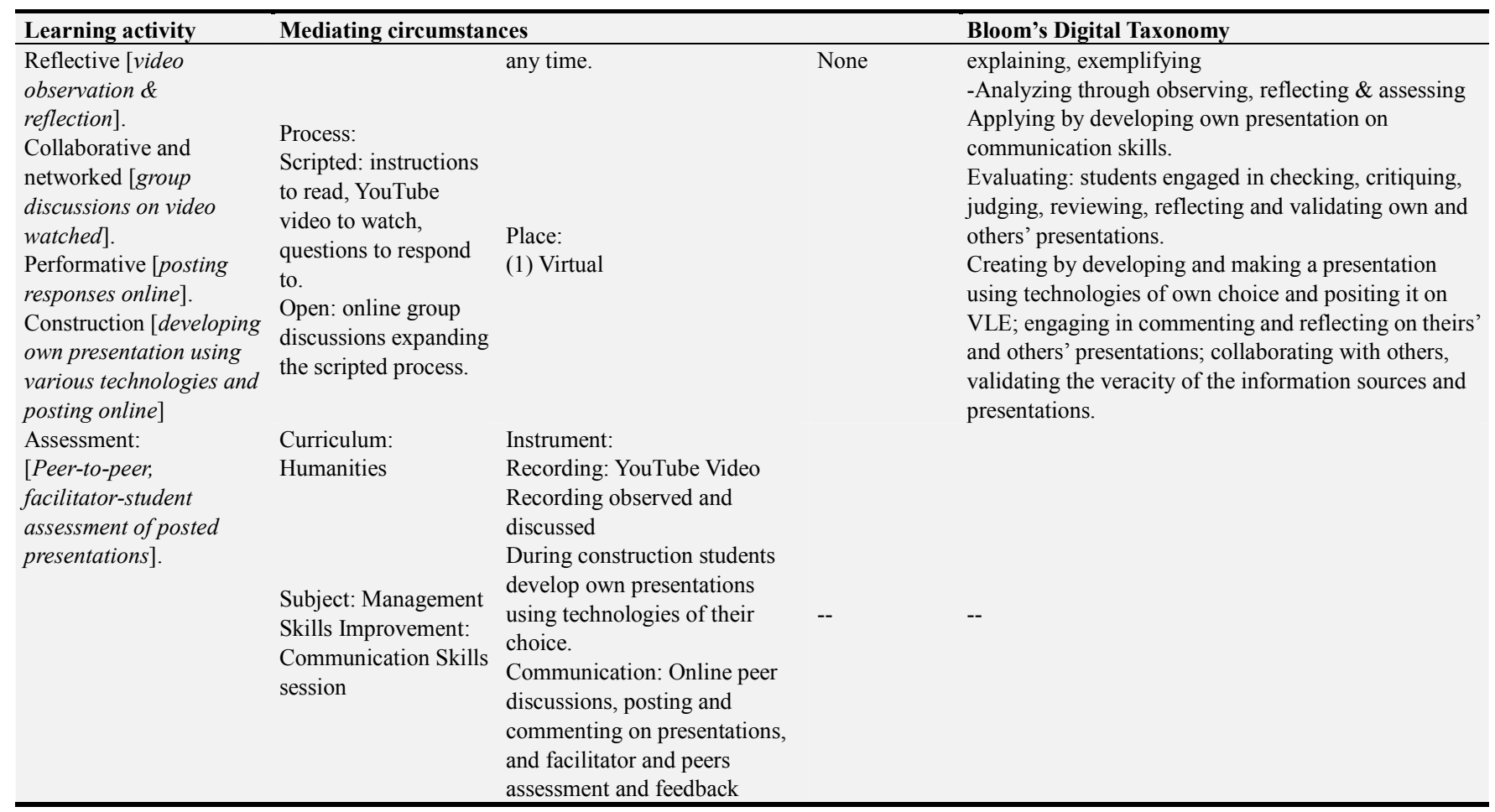

Source: Adopted and modified from [3].

\section{Analysis and Discussion of Findings}

\subsection{Analysing and Matching Learning Tasks and YouTube Using Bower's Affordance Analysis}

The researchers analyzed and matched the learning tasks to the selected tool. The learning activities selected and designed on the VLE were derived from the educational purpose, specific objectives and learning outcomes (highlighted earlier in this paper) intended to promote various forms of interaction, provide real time feedback to facilitators and students, and motivate students to learn individually and in groups to achieve the intended learning outcomes.

\subsection{Analysis of Learning Tasks Using Bloom's Digital Taxonomy}

As noted earlier, the design of the learning activities was guided by Anderson's [11] framework and Bloom's digital taxonomy. The researchers again analyzed the learning activities based on Bloom's digital taxonomy [13]. The first online activity students engaged with was to read the online session on communication styles. This was intended to give them background understanding of the session, its overall and specific educational objective (s), content scope, reference materials, and to provide a link between the familiar and unfamiliar, i.e. scaffolding [Rubens, et al., cited in Bower, 12, page 4]. With reference to Bloom's digital taxonomy, the reading activity as a Lower Order Thinking Skill (LOTS) would enable students remember and understand the session and prepare them to be able to apply, analyze, evaluate and create. In terms of interaction, the reading activity provided opportunity for students to interact with session content in preparation for them to be able to interact with peers and with the facilitator.

The second task was to watch the video; Introduction to Curriculum design posted on the VLE [31]. This activity as is a 'LOTS,' intended to anchor students' perception and prepare them for guided responses [13] as watching combined with listening helped them to remember and understand the video structure and content.

After watching the video, students used 'the online discussion forum to explain the nature of communication taking place,' and 'analyze the enablers and barriers to communication in the video'. According to Bloom, 'explaining' is LOTS and 'analyzing' is HOTS. 'Explaining' enabled students to have a general comprehension of the video to prepare them for an in-depth analysis of the enablers and barriers to communication. Analysis involved comparing, attributing, structuring and outlining [13].

Based on the video and the researchers' experiential knowledge, students were required to 'select a topic of your choice on which you want to communicate to an audience of your choice. Using various technologies make a presentation of your selected topic. Make a video recording of your presentation and upload it online. The above tasks tapped several HOTS including decision making/evaluating from many choices to select a topic and audience, applying the knowledge and skills acquired within and outside the session boundaries, and creating, i.e. making, recording and uploading their presentations (a task they did not engage in due to time constraints). After uploading their presentations, students were to 'view and constructively critique two of your colleagues' presentations,' which according to Bloom involves analyzing and evaluating others' artifacts. This and 
the former tasks exploit various forms of interaction as provided for by Anderson [11] as well as social skills of knowledge sharing and networking. The final task was to 'complete and submit the self-evaluation tool,' which would enable students to assess and evaluate their own learning.

In addition to Bloom's digital taxonomy, the researchers were guided by other criteria for selecting learning activities which included: validity, relevance/utility, comprehensiveness, variety, suitability, feasibility and interesting $[29,30]$ and the principles of adult learning [25].

From the above analysis, the learning process moved along a continuum from LOTS to HOTS and the more lecturers tap into HOTS the more students take charge of their own learning and acquire hands-on practical skills. As one designs the learning tasks, there is need to be mindful of the broader picture, for instance, the forms of interaction that should be exploited and the technologies that could be used.

\subsection{Analysis of YouTube and the VLE Using Bower's Affordance Analysis}

Having formulated the educational purpose and specific session objectives, and designed the learning activities guided by Bower's affordance analysis e-learning design methodology [12, page 8], the researchers recorded and posted a video on communication skills to the VLE using YouTube. The assumption was that the video could enable them 'scaffold progressive inquiry', 'structure and coordinate activity' and 'support community building' [Rubens, et al., cited in 12, page 4].

Affordances are the action potentials of the technologies or their utility to the user. Bower designed a framework of analysis that guides the development of '...e-learning experiences by matching the affordance requirements of tasks with the affordances offered by the available technologies...' [12, page 3]. The researchers found the framework very useful in selecting YouTube as a tool to use to improve online interaction. This choice was further guided by Anderson's analytical framework [11] and Bloom's digital taxonomy [13].

The YouTube video was selected because it has media affordances, i.e. view-ability due to its images, watch-ability and listen-ability [12]. A video is one tool that combines the audio-visual characteristics, which appeal to students' senses, thereby making learning more interesting. A video has spatial affordances, and for that reason, the researchers were able to record the video using a video recorder, save it on a computer, upload it as a YouTube, copy the video from the Internet and paste it on the VLE. The video screen can also be enlarged or reduced and the volume increased or reduced depending on the user's preference. The video can also be saved and played on compatible tools including on a smart phone. Because of these affordances, a YouTube video is quick and easy to access.

The video has a temporary affordance, in that it can be accessed anytime, anywhere, in addition to having the ability to be recorded, retrieved, played, paused or stopped and played-back. In the current study, the students were able to save and playback the video in a flexible manner, meaning that videos work well in asynchronous training programmes. Another affordance of the YouTube video is its navigation ability and link-ability, i.e. the ability to scroll forward/backward and to be linked with other tools to further enhance interactivity and learning. Consequently, PowerPoint slides and Prezi, Blog posts, podcasts, vodcasts and other relevant links such as online articles, learning sites can be incorporated. The video URL can be copied and pasted in a PowerPoint or word presentation for reference. Related to the above, videos have synthesis affordances, i.e. they can be combined with other tools and the contents of resources can be integrated [12]. Videos have technical affordance, in that they can be used on various platforms, including the VLE.

The YouTube video has access-control affordances to allow the discussion groups to freely access, view the videos and exchange knowledge on what they have viewed. It has usability affordances in that users can easily manipulate it for learning at their own pace. Carefully selected videos also have the aesthetic affordance, since good and interesting videos are appealing to the eye in terms of color, movement, and is therefore likely to hold students' attention.

Another affordance not noted in Bower [12] but also vital is the videos' potential to promote creativity. Because of this affordance students were required to make their own video presentations using various technologies, record and upload them on the discussion forum. In this way Bloom's digital HOT skill of creating artifacts was also nurtured.

Because of these affordances, YouTube can encourage and expand collaboration, for instance through group YouTube projects and can according to the EDUCAUSE Horizon Report [1] enhance personalised learning, enable students to manage the content they use, the learning pace and style, and ways in which they demonstrate their knowledge, thereby making learning settings flexible and adaptable. In the current study, students watched the video and engaged in group discussions. They were also required to assess their peers' presentations, thereby reducing teacher-centeredness and promoting independent and group study skills through student-content [video content], student-student interaction and nurturing HOTs of analysing, evaluating and creating [13].

The VLE in this study was the secondary tool used to support YouTube, which was the primary focus. As a tool, the VLE has a variety of affordances including media, spatial, temporal, navigation, emphasis, synthesis, access-control, technical, usability, aesthetics, and reliability [12]. In addition, the VLE can be structured and re-designed to fit the users' needs [3].

\subsection{Analysis of YouTube and the VLE Using Bower's Affordance Analysis}

In this section, using a matrix (Table 3) the researchers matched the affordances of the learning tasks with the affordances of the selected YouTube videos. 
Table 3. Matched learning tasks and selected YouTube videos.

\begin{tabular}{|c|c|c|}
\hline $\mathbf{S} / \mathbf{N}$ & Learning task & YouTube video affordance \\
\hline 1 & Read the session on communication skills within this module & -- \\
\hline & & $\begin{array}{l}\text { Most of YouTube's affordances were exploited under this learning } \\
\text { activity, i.e.: } \\
\text { media:- students were able to view/watch the video; } \\
\text { spatial:- video was copied from the Internet and pasted on VLE, } \\
\text { screen could be enlarged/reduced, volume could be increased/reduced, } \\
\text { video was saved and played on compatible tools including on smart } \\
\text { phones, } \\
\text { temporal: accessed on VLE, smart phone, etc., anytime, } \\
\text {-navigation ability and link-ability:- ability to scroll } \\
\text { forward/backward and linked with other tools to further enhance }\end{array}$ \\
\hline 2 & Watch the video posted on the VLE & $\begin{array}{l}\text { interactivity and learning, } \\
\text { synthesis:-video uploaded/downloaded on VLE, smart phones, etc., } \\
\text { access-control:- students in their discussion group could freely access, } \\
\text { view video and share knowledge, } \\
\text { usability:- video easily manipulated for learning and other purposes. } \\
\text { aesthetic:-selected video was interesting and appealing to hold } \\
\text { students' attention, } \\
\text { technical:- YouTube videos can be used on various platforms, } \\
\text { including the VLE. } \\
\text { create-ability:- students could make own video presentations, record } \\
\text { and upload them on the discussion forum. }\end{array}$ \\
\hline 3 & $\begin{array}{l}\text { Use the online discussion forum to respond to the following questions and } \\
\text { post your response before Tuesday. } \\
\text { a) Explain the nature of communication taking place in the video. } \\
\text { b) Analyze the enablers and barriers to communication in the video. } \\
\text { c) Comment on two of your colleague's responses in a discussion forum by } \\
\text { Monday lunch time. }\end{array}$ & $\begin{array}{l}\text { VLE was used because it has media, spatial, temporal, navigation, } \\
\text { emphasis, synthesis, access-control, technical, usability, aesthetics, } \\
\text { and reliability affordances. It can be structured and re-designed to fit } \\
\text { the users' needs. }\end{array}$ \\
\hline 4 & $\begin{array}{l}\text { Based on the video and knowledge acquired in this session and elsewhere, } \\
\text { a) Read about the types of curriculum designs and make a ten-minutes } \\
\text { presentation critiquing five curriculum designs of your choice in Uganda' } \\
\text { setting. Use a variety of technologies you think can enhance your } \\
\text { presentation and convey your message to your students. } \\
\text { Submit your work on VLE on Tuesday next week. } \\
\text { b) Comment on two of your colleagues' presentations. Post your comments } \\
\text { on VLE by Thursday next week. }\end{array}$ & Similar to 2 above. \\
\hline 5 & View and constructively critique two of your colleagues' presentations. & Similar to 3 above. \\
\hline 6 & Complete and submit the self-evaluation tool. & Similar to 3 above \\
\hline
\end{tabular}

After analyzing the affordances of the learning tasks and matching them with the affordances of the video the assignment was uploaded on the VLE as illustrated in Figure 3 below.

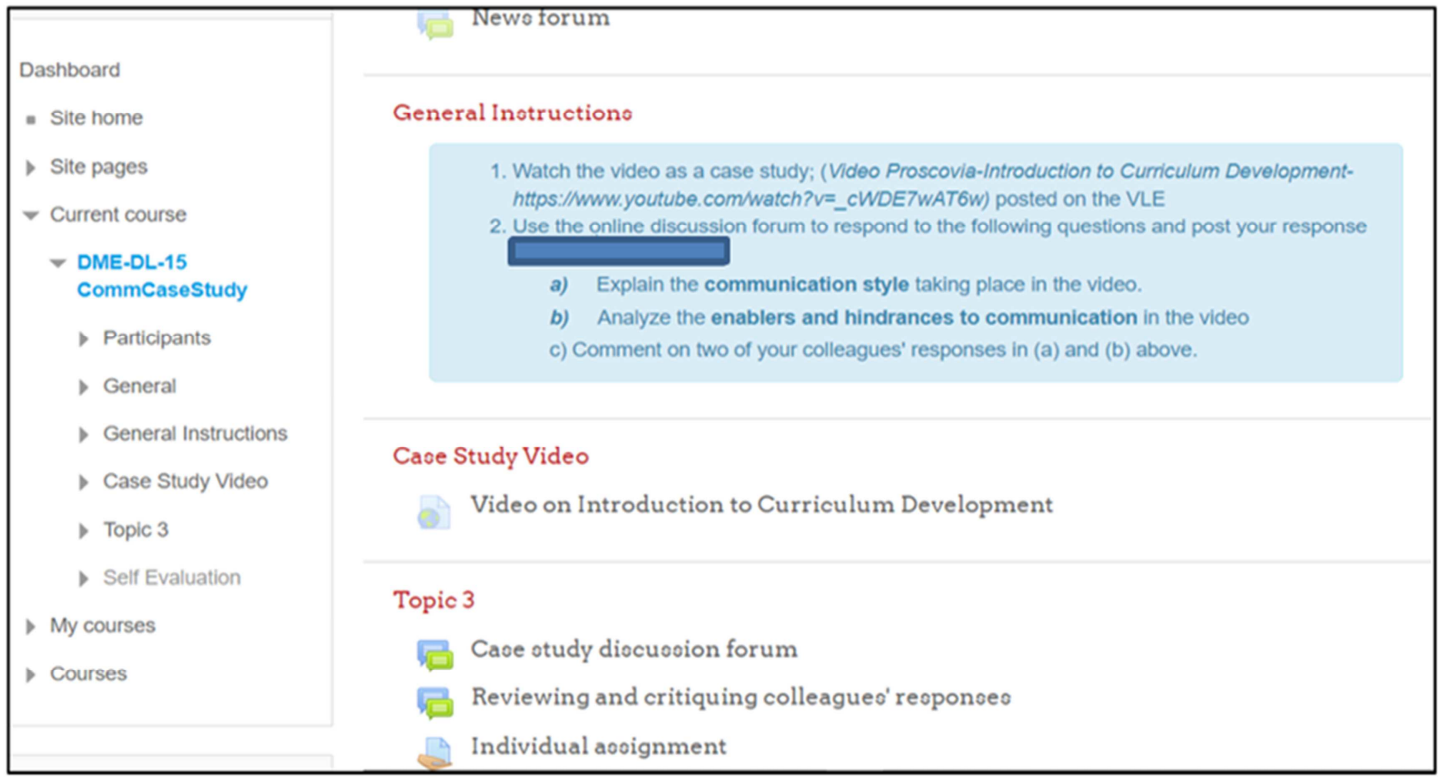

Figure 3. Learning activities designed to promote interaction and achievement of learning outcomes 


\subsection{Proof of Concept}

Below are some illustrations; Figures 4 (a), (b) and (c) showing evidence of student-content interaction, student-student interaction and student-teacher interaction.

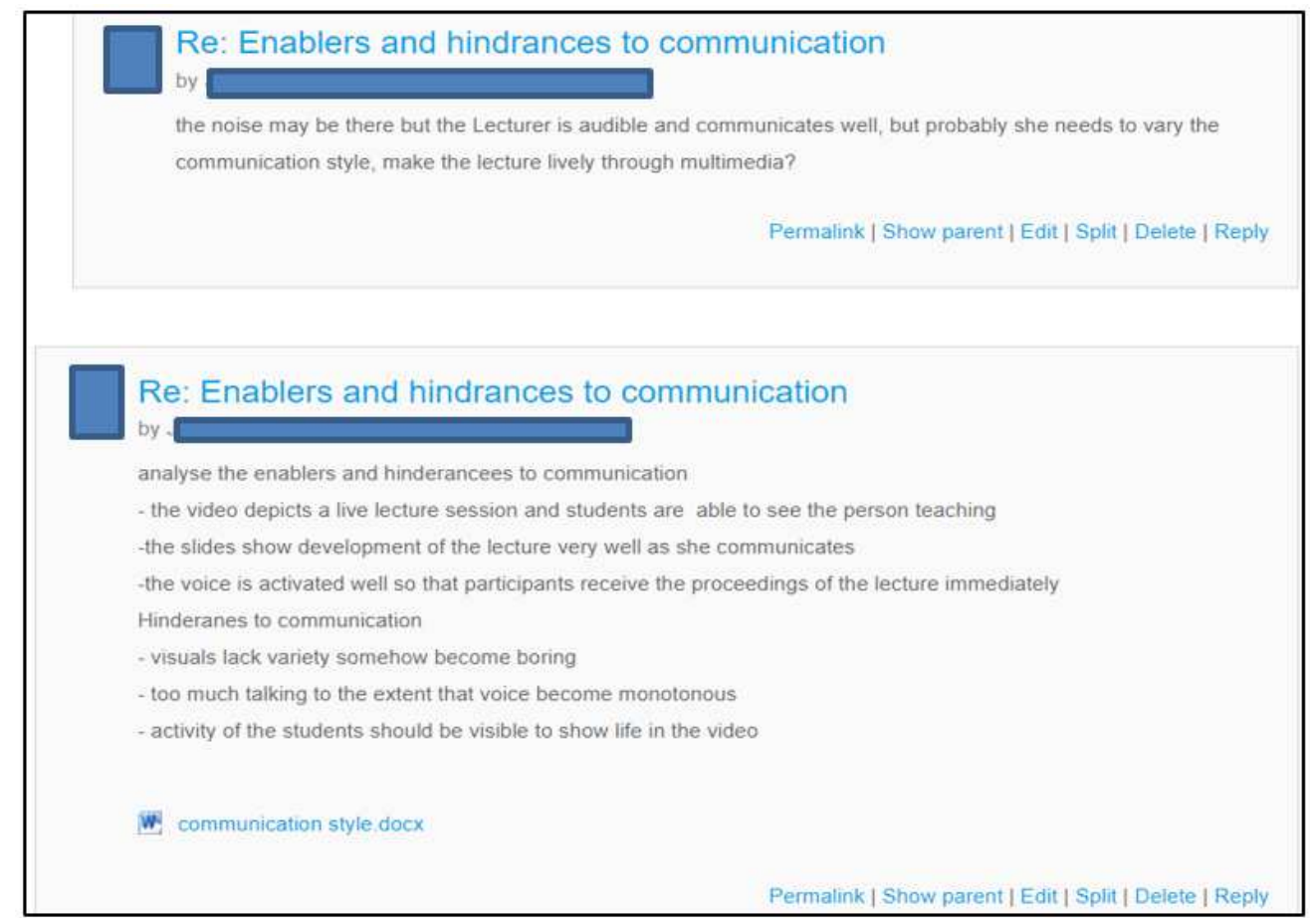

(a)

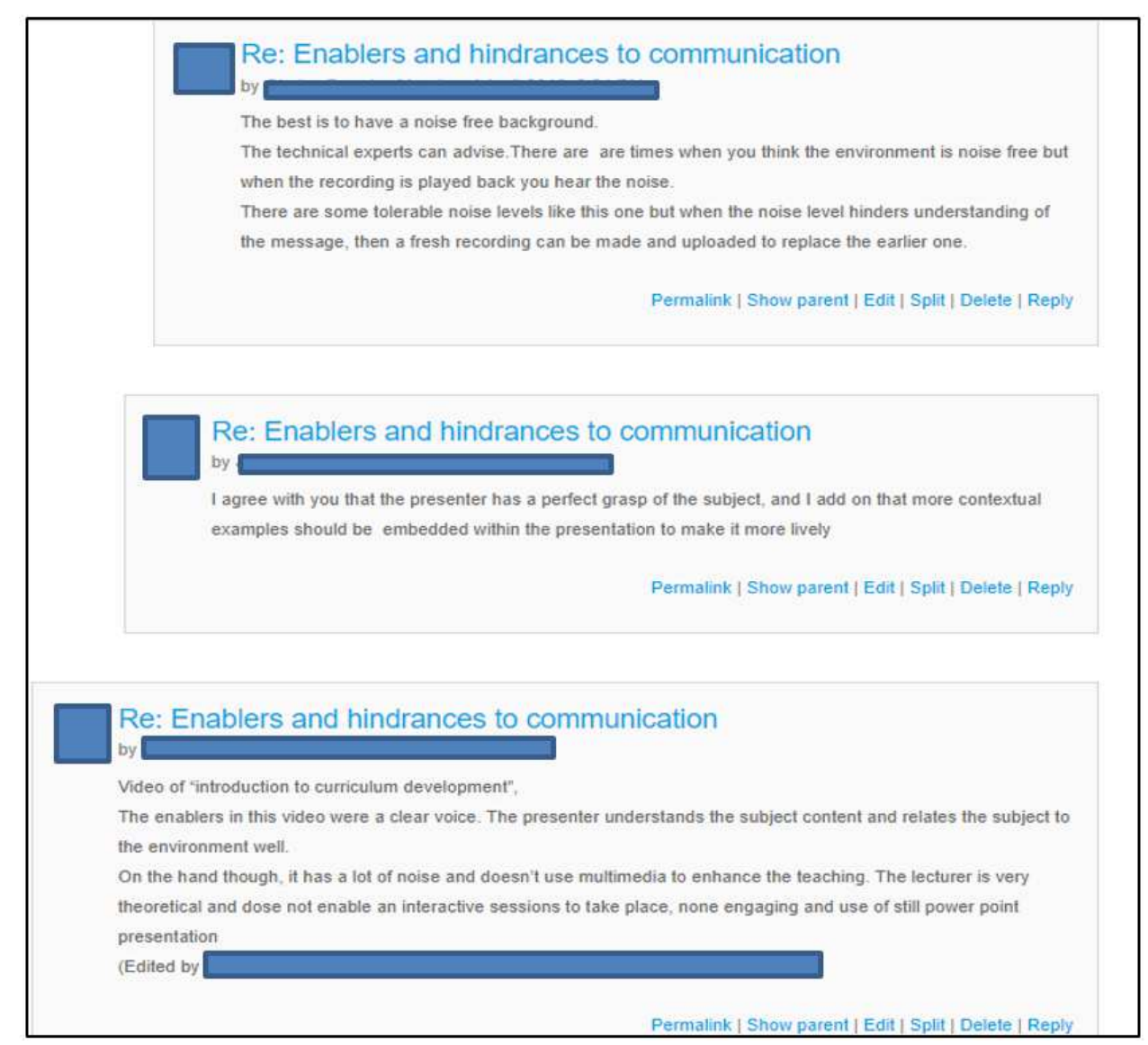

(b) 


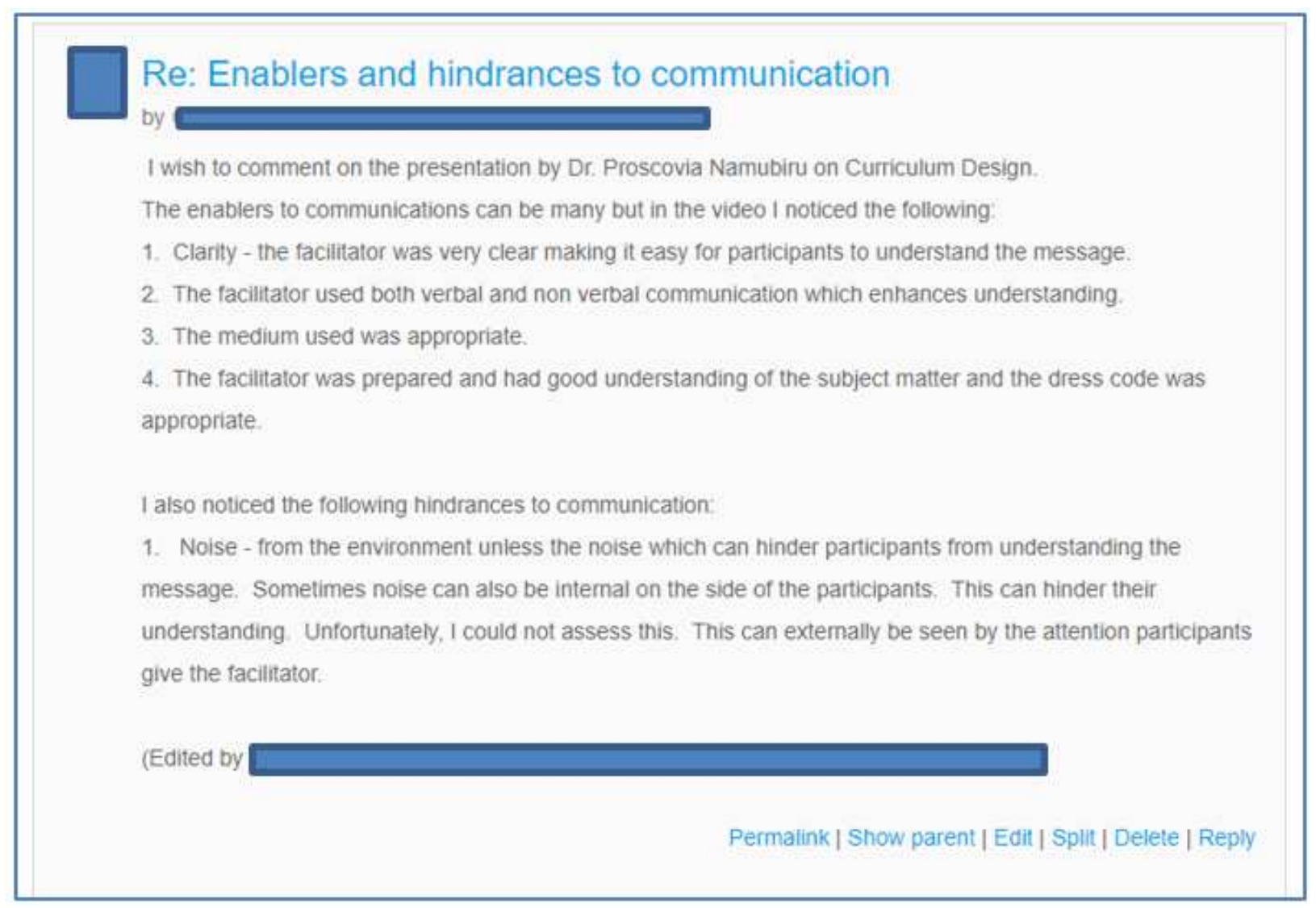

(c)

Figure 4. (a). Example of student-content interaction on enablers and barriers to communication. (b). Example of student-student interaction. (c): Example of student-teacher interaction.

The original design of this session had no interactive activities and there was no evidence to show the presence and nature of interaction, other than the reading of the online course handbook as the students' sole reference material. The introduction of YouTube videos not only extended students' knowledge and skills in communication beyond the handbook, but also helped them interface with another technology and enriched their learning through various interactions as illustrated in Figures 4 (a), (b) and (c) above. If well planned, such interaction is richer than a $\mathrm{f} 2 \mathrm{f}$ session.

Anderson's online interaction framework [11], Bloom's digital taxonomy [13], Bower's affordance analysis [12] and the constructivist theory are useful thinking tools in developing online learning activities and in identifying and matching higher order learning activities to suitable educational technologies. It is noted that '...framework [s] can help discern what is intrinsic to the technology and what emerges from the ways in which teachers and learners appropriate the technology' [3, page 14]. In the current study, it would have been challenging and unstructured to work in the absence of the frameworks, especially in the domain of e-learning.

Inherent in the frameworks and learning theories are procedures, which guide the process of designing online learning tasks. For instance, the researchers found Bower's affordance analysis e-learning design methodology [12] informative in structuring the design and implementation of the learning activities starting with identification of the educational goal (s) to designing the e-learning tasks matched with the e-learning tools based on their affordances. Further, based on the assessment questions posted on the VLE, lack of understanding of Bloom's digital taxonomy and the need to emphasize HOTs leads designers to ask LOTS. Perhaps because online education is relatively young in Uganda' higher education institutions, educational materials are uploaded on the VLE in a direct transfer format from offline programmes. This hinders interactivity, variety and the tapping of HOTS, which for instance, ought to be exploited using the VLE.

The thinking tools used in the current study and elsewhere require a shift in the thinking of offline course designers and implementers when designing online programs. Key in the process is the need to exploit the various forms of interaction provided [11] showing a shift in the position of the teacher and the student. The teacher plays more of a facilitative and mentoring role, whereas the student is responsible and accountable for his/her own learning.

\section{Recommendation}

We infer from this study that online learning interactions 
between distanced students, content and teacher can be fostered using the following six steps:

1) Select a shared online platform that is easily accessible by students. Use the platform for both communication and knowledge sharing with students. Context will be important in informing this decision.

2) Design a learning activity that requires watching a YouTube video to accomplish. One needs to bear in mind that watching a YouTube video on a mobile phone, for example, requires that students had data. This could be a barrier for some students. So rather than sharing the link, a teacher may download the video and upload it on the VLE. The assumption is that at some institutions, access to the VLE could be zero rated.

3) Provide opportunities for students to reflect individually and share their reflections with the group. It is important that students watch videos with questions in mind. This allows them to reflect as they watch the videos. Writing a reflection provides a deeper sense of engagement with 'content' - the videos.

4) Provide students opportunity to engage with peers' work through reflections and making comments - having watched the same video. This provides students access to other students' work, to learn from one another and enriches students' learning experience.

5) Allow students to design learning activities for the class, and this will allow them to role play the teacher.

The above steps ensure that higher order thinking skills are achieved. It also fosters deep and meaningful learning.

\section{Conclusion}

From the foregone, the researchers draw the following conclusion:

Identifying and matching the learning activities to suitable educational technologies is not linear, but a back and forth reflection and action until the desired outcome is arrived at. There should be careful thought invested into the decisions course designers make in selecting learning activities and matching these to suitable technologies. In designing educational systems, one has to understand how tools interplay with cognition, and this understanding guides the selection of technology [12]. Bower therefore advocates for a methodology rather than a prescription, which the researchers entirely agree to.

Since interactivity is the primary criterion for selecting media for educational delivery (Bates, 1991 cited in 11, page 44] the educational purpose provides the basis for selecting technology, and suitable technology (ies) play a fundamental role in fostering learning.

Online education has several advantages including the ability to use multimedia, fostering flexible and collaborative learning (as exemplified in Figures $4 \mathrm{a}, \mathrm{b}$ and c), as well as tapping HOTs with the aim of preparing students for work practice through '...virtual teaming or collaboration, critical thinking, and enhanced student engagement...' [4, page 29].
Using a variety of media such as audio, linguistic, visual, gestural, spatial has the potential to tap several affordances $[12$, page 6] and therefore build multiple cognitive skills among the learners compared to using a single technology. This observation is also made in a study on multimedia to enhance blended learning experience in constrained low bandwidth environment [33].

Using online educational technologies in teaching and learning does not necessarily mean that the educational process is interactive. In Reference [34, page 51], technology is not used for its own sake, but to extend the potential of learning. Drawing on Bower's [12, page 5] conceptualization of 'affordances' the functionality of the technology should be carefully analyzed to ensure a match between the technology and the task as this provides learners with the desired but also targeted learning opportunities. This is a pointer to the possibility of an underutilization of the VLE affordances in higher education institutions in Uganda.

Online learning affords various forms of interaction which should be exploited by lecturers and students. However, this depends on their perception and commitment to foster interaction, the nature of curriculum design [for instance, whether it is teacher/subject, problem-based, competence/outcomes based or learner-centered], availability of various technologies, and the contribution of institutional leadership.

As noted by Palloff and Pratt in a virtual learning environment, the teacher becomes the 'guide on the side,' students play a much more active role in their learning; and collaboration between teacher-student and peer student-student are essential to succeed [15]. Further, technology in itself cannot transform pedagogy; it is the teacher and students who do so.

\section{Acknowledgements}

The Authors acknowledge management and staff of the higher education institution used as a case study. Carnegie and Melon Foundations are acknowledged for the scholarships offered to undertake the PGD in Education Technology at the University of Cape Town and all our course facilitators for building our capacity as scholars, practitioners and researchers.

\section{References}

[1] M. Brown, M McCormack, J Reeves, D. Christopher Brooks, S. Grajek, B. Alexander, M. Bali, S. Bulger, S. Dark, N. Engelbert, K. Gannon, A. Gauthier, D. Gibson, R. Gibson, B. Lundin, G. Veletsianos, and N. Weber, EDUCAUSE Horizon Report, Teaching and Learning Edition, Louisville, CO: EDUCAUSE, 2020.

[2] D. Ng'ambi and V. Bozalek, "Leveraging informal leadership in higher education institutions: A case of difussion of emerging technologies in a southern context," in British Journal of Educational Technology, vol 44, no. 6, 2013, pp. 940-950. 
[3] M. Sharples, C. J. Crook, Ian, D. Kay, I. Chowcat, K. Balmer and E. Stokes, New modes of technology-enhanced learning: Opportunities and challenges, pp. 1-53, 2009, downloaded from http://www.becta.org.uk on the 18-02-16.

[4] K. Kyong-Jee and J. C. Bonk, "The future of Online teaching and learning in higher education: The survey says..." EDUCAUSE Quarterly, vol. 4, pp. 22-30, 2006.

[5] L. Price and A. Kirkwood, "Using technology for teaching and learning in higher education: a critical review of the role of evidence in informing practice," in Higher Education Research and Development, vol. 33 , no. 3 pp. 549-564, 2014, Available from http://oro.open.ac.uk/34804/2/682F5A36.pdf.

[6] M. Aparicio, F. Bacao and F., T. Oliveira, "An e-Learning Theoretical Framework," in Journal of Educational Technology \& Society, vol. 19, no. 1, pp. 292-307, 2016, downloaded from https://www.jstor.org/stable/10.2307/jeductechsoci.19.1.292 on $14^{\text {th }}$ Oct. 2019.

[7] J. Ahlquist, "Trending Now: Digital Leadership Education Using Social Media and the Social Change Model," in Journal of Leadership Studies, vol. 8, pp. 57-60, 2014, Available from http://onlinelibrary.wiley.com/doi/10.1002/jls.21332/epdf.

[8] R. Baguma, E. Bagarukayo, P. Namubiru Ssentamu, C. Brown and T. Mayisela, "Using WhatsApp in teaching to develop higher order thinking skills: a literature review using activity theory lens," in International Journal of Education and Development using Information and Communication Technology, vol. 15, no. 2, 2019.

[9] E. Bagarukayo, D. Ng'ambi, R. Baguma and P. Namubiru Ssentamu, "Using acebook to transfer knowledge into practice and aid student, lecturer and content interaction: a case of Bachelor of Information Technology undergraduate students at Makerere University," in Proceedings of the $9^{\text {th }}$ International Conference on Computer Supported Education, vol. 1, pp. 402-410, 2017.

[10] E. Bagarukayo, P. Namubiru Ssentamu, T. Mayisela and C. Brown, "Activity theory as a lens to understand how Facebook develops knowledge application skills," in International Journal of Education and Development using Information and Communication Technology, vol. 1, no. 4, pp. 270-301, 2016.

[11] T. Anderson, "Toward a theory of online learning; Theory and practice of online learning," vol. 2, pp. 15-44, 2008.

[12] M. Bower, "Affordance analysis - matching learning tasks with learning technologies," in Educational Media International, vol. 45, no. 1, pp. 3-15, 2008.

[13] A. Churches, "Bloom's Digital Taxonomy," 2012, retrieved from http://edorigami.wikispaces.com/Bloom $\% 27 \mathrm{~s}+$ Digital_Taxonom y on $21^{\text {st }}$ April, 2018.

[14] R. Lynch and M. Dembo, "The relationship between self-regulation and Online learning in a blended learning context," in International Review of Research in Open and Distance Learning, vol. 5, no. 2, 2004, retrieved on $1^{\text {st }}$ March, 2016 from http://files.eric.ed.gov/fulltext/EJ853865.pdf.

[15] R. M. Palloff and K. Pratt, Building learning communities in Cyberspace: Effective strategies for the online classroom. San Francisco: Jossey-Bass, 1999.

[16] D. Wohlfarth, D. Sheras, J. L. Bennett, B. Simon, J. H. Pimentel and L. E. Gabel, "Student perceptions of learner-centered teaching," in Insight: A Journal of Scholarly
Teaching, vol. 3, pp. $67-74,2008$.

[17] B. Higgs and M. McCarthy, "Active learning - from lecture theater to field-work," in O'Neill, G., Moore, S., McMullin, B., (Eds) Emerging issues in the practice of university teaching and learning, Dublin: AISHE, 2005.

[18] G. O'Neill and T. McMahon, "Student-centered learning: What does it mean for students and lecturers?" in O'Neill, G., Moore, S., McMullin, B., (Eds)., Emerging issues in the practice of university teaching and learning, Dublin: AISHE, 2005.

[19] P. Ramsden, Learning to Teach in Higher Education. London: Routledge, 1992.

[20] D. Ng'ambi and A. Lombe, "Using Podcasting to facilitate student learning: A constructivist perspective," in Journal of Educational Technology \& Society, vol. 15, no. 4, pp. 181-192, 2012.

[21] Uganda National Council for Higher Education, (2008) Quality assurance framework for universities and the licensing procedure for higher education institutions, Kampala, 2014.

[22] J. Biggs, "Enhancing teaching through constructive alignment," in Higher Education, vol. 32, pp. 347-64, 1997.

[23] J. Biggs, Teaching for quality learning at university. Buckingham: SRHE/OU Press, 1999.

[24] R. Donnelly and M. Fitzmaurice, "Designing modules for learning," in O'Neill, G., Moore, S., McMullin, B., (Eds) Emerging issues in the practice of university teaching and learning, Dublin: AISHE, 2005.

[25] M. Knowles, The adult learner: a neglected species. 4th Ed. Houston: Gulf Publishing Company, 1990.

[26] J. Bbuye and R. K. Mwogeza, "Programme design, layout and management of distance learning: A case of UMI distance learning programme," Unpublished, 2014.

[27] B. Sweeny, "The principles of adult learning: based on the ideas of John Goodlad," Best Practice Resources, 2008 retrieved from www.businessmentorcenter.com/AdultLrng.php on the $3^{\text {rd }}$ of January, 2011.

[28] M. J. W. Thomas, "Learning within incoherent structures: the space of online discussion forums," in Journal of Computer Assisted Learning, vol. 18, pp. 351-366, Blackwell Science Ltd., 2002.

[29] P. P. Bilbao, P. I. Lucido, T. C. Iringa and R. B. Javier, Curriculum development. Quezon City: Lorimar Publishing, Inc., 2008.

[30] D. K. Wheeler, Curriculum process, Surrey: Unibooks, Hodder and Stoughton, 1967.

[31] YouTube Videos on communication skills: https://www.youtube.com/watch?v= cWDE7wAT6w.

[32] L. Cohen, L. Manion and K. Morrison, Research methods in education (7th ed.) Abington, Oxon: Routledge, 2011.

[33] N. A. Suhail, J. T. Lubega and G. Maiga, "Multimedia to enhance blended learning experience in constrained low bandwidth environment," in Proceedings from S. K. S. Cheung, J. Fong, L. Kwok. K. Li, and R. Kwan, Hybrid Learning: $5^{\text {th }}$ International Conference, LNCS, Vol. 7411, pp. 362-372, Springer-Verlag Berlin Heidelberg, 2012. 
[34] JISC National e-books observatory project, Key findings and recommendations, final report, London, 2009. 